\title{
Fighting for the poverty: a case study for human migration in the context of sustainable dryland farming development in the Southern Ningxia Hilly Area
}

\author{
Yongqing MA $(\bowtie)^{1,2}$, Jie CHEN ${ }^{1}$, Shuqi DONG ${ }^{3}$, Lun SHAN ${ }^{1}$ \\ 1 The State Key Laboratory of Soil Erosion and Dryland Farming on the Loess Plateau, Institute of Soil and Water Conservation, \\ Northwest A\&F University, Yangling 712100, China \\ 2 College of Natural Resources and Environment, Northwest A\&F University, Yangling 712100, China \\ 3 College of Agriculture, Shanxi Agricultural University, Taigu 030801, China
}

\begin{abstract}
The Southern Ningxia Hilly Area is one of the most impoverished areas of Ningxia Hui Autonomous Region (a province) of China due to an economy that mainly relies on agriculture, which is affected by droughts in two out of every three years. Government programs have attempted to develop an increased and sustainable level of scientifically based agricultural production while restoring the environment. However, since the population exceeds the capacity of the land to adequately support it, a program is underway to move 350000 people to more suitable locations. This paper outlines the past improvements to the Southern Ningxia Hilly Area and considers future development in the context of migration for ecological reasons.
\end{abstract}

Keywords agricultural production, animal husbandry, development strategy, ecological migration

\section{Introduction}

The Southern Ningxia Hilly Area (SNHA) is located on the Loess Plateau in a windy and sandy arid area at Ningxia Hui Autonomous Region (NHAR, a province of China, is located in northwest China, on the upper reaches of the Yellow River. It is one of China five autonomous regions inhabited by the minority groups, its borders Shaanxi Province in the east, the Inner Mongolia Autonomous Region in the north, and Gansu Province in the south), where the ecological systems are very fragile. As one of the most impoverished places in China, before year of 2000,

Received April 24, 2014; accepted May 4, 2014

Correspondence: mayongqing@ms.iswc.ac.cn people found it difficult even to feed and clothe themselves adequately [1]. Drought is a frequent phenomenon in Southern Ningxia Hilly Area, occurring on average in two out of every three years; half of the droughts are severe. The droughts and other natural disasters, and the susceptibility of the soils to wind and water erosion, restrict agricultural development of SNHA [2]. Furthermore, the human population exceeds the capacity of the area to support it sustainably.

The national and local governments have implemented a poverty alleviation strategy in SNHA that was both wideranging and long-term, and which has achieved great success $[3,4]$. The strategy includes plans for agricultural and ecological sustainability, and economic development. In the past decade, economic development was rapid and the shortages of food and clothing were largely eliminated [5]. However, development needs to be consistent and address every aspect of life in order to eliminate poverty completely [6]. Furthermore, since the factors that influence economic development change with time, plans must be flexible and adapt to the changing economic and social situations.

Scientific research by the Chinese Academy of Science (CAS) has reinforced the governmental policies enacted on the ground in order to improve the agricultural industry and the environment. This article introduces the Guyuan Ecological Station of CAS history of scientific research and achievements in the Guyuan experimental zone, which is located in Guyuan city of NHAR and discusses the potential for sustainable agricultural development in SNHA.

Furthermore, one of the policies implemented by the provincial government of NHAR in 2010 has been to promote migration from SNHA to alleviate the population 
pressures on the environment. This article discusses the policy and its consequences for the region.

\section{The Sourthern Ningxia Hilly Area and study area}

\subsection{Geographical location, features and climate}

The Southern Ningxia Hilly Area (SNHA) includes eight counties (Xiji, Haiyuan, Guyuan, Longde, Pengyang, Jinyuan, Tongxin and Yanchi). There are four mountainous areas (Zhongwei, Zhongning, Wuzhong, and Lingwu) covering $39500 \mathrm{~km}^{2}$, which constitute $76.3 \%$ of the total land area of NHAR. The terrain in the region often has the broad valley loess hills typical of the Loess Plateau. The mean altitude is $1750 \mathrm{~m}$ and the elevation rise is $234 \mathrm{~m}$. The Yellow River flows through land to the north of the region permitting some irrigation.

The climate is semi-arid to arid. The mean annual precipitation is $480 \mathrm{~mm}$, the most of which (59\%-66\%) falls between July and September in intense rainstorms that generate runoff. The mean temperature is $7^{\circ} \mathrm{C}$; The annual dryness is 1.55; and there are 152 frost free days per year [7]. The evaporation capacity is $900-1760 \mathrm{~mm}$ per year.

The region experiences some of the most severe water shortages in China and drought is a common occurrence, affecting two in every three years. It has a water resource of $720 \times 10^{6} \mathrm{~m}^{3}$, of which $475 \times 10^{6} \mathrm{~m}^{3}$ are available, equivalent to $327 \mathrm{~m}^{3}$ per person or $4.3 \mathrm{~m}^{3} \cdot \mathrm{hm}^{-2}$ [2].

\subsection{The Guyuan experimental area and ecological station}

To conduct research on agriculture and the ecology of the region, the Guyuan experimental area has been established in the SNHA. The landscape, climate, soil, vegetation and geomorphology are considered to be representative of those found in the Loess Plateau hilly region. The Guyuan experimental area is located in the watershed of the Jing and Qing Rivers. It also straddles the partition between two different landform types and ecological zones due to the presence of a fault line marked by the Liupan Mountains.

In 1976, 50 scientists from 14 institutes of biological science in the CAS were assigned to SNHA to carry out research. The Institute of Soil and Water Conservation (ISWC) in Yangling, Shaanxi Province was one of these institutes. In 1982, the ISWC set up a research base in Shanghuang village, Hechuan Town, Yuanzhou Distric of Guyuan City within the NHAR. In 1986, plans to enlarge the research base into the Guyuan Ecological Station were made and this was accomplished ten years later. The Station was then supervised by both the CAS and the NHAR Government. It later became a field teaching test base for the Northwest A\&F University. More than 100 scientists over the past four decades have participated in the study of the Guyuan ecological experimental area.

\section{The problems confronting SNHA and the proposed solutions}

The frequent occurrence of drought, low crop yields and population expansion are the key factors that have led to deterioration of the ecological environment. This in turn hinders the economic development of the SNHA [8]. In 1949, the population of Guyuan was 476000 but by 1999 it had quadrupled to 1.92 million. The population density thus increased from 28.6 to 114.5 per $\mathrm{km}^{2}$ over this period [8].

Governments at the local and national level have made a number of long-term plans to solve the problems of the SNHA. These plans attempt to increase agricultural productivity to sustainable levels while decreasing pressures on the natural environment. In accordance with these plans, scientists from the ISWC have been involved in the continuous investigation of the natural environment and in the development and testing of scientifically-based agricultural practices that are appropriate for the Guyuan experimental zone and the region as a whole. At all times, they have been involved with extension to the local farmers and collected feedback on the experiences of the farmers in order to improve their recommendations. Although the following are mostly presented individually, the techniques were in practice integrated to form coherent, rational farming practices.

\section{Improving agriculture}

\subsection{Increasing crop yields with fertilizer}

The investigating scientists came to the conclusion that although water shortages were the key problem in the region, appropriate use of fertilizer could still increase yields; insufficient applications of fertilizer had formerly been a problem, usually due to the initial costs that were beyond the means of poor farmers of SNHA [9]. In addition, the scientists proposed deep applications of fertilizer to enrich the nutrient poor soils of the southern Ningxia Hilly Region. The government is responded by providing large quantities of fertilizers, and by financing and encouraging the deep fertilization. Once soils had been enriched, numerous crop-specific techniques were introduced that improved the cultivation of crops in regions with water shortages [10-12].

\subsection{Increasing water use efficiency}

Scientists conducted experiments and then helped the local farmers to adopt and develop appropriate techniques for water-harvesting, water conservation and storage, and micro-irrigation, thereby increasing the region's water use efficiency [2]. These scientists convinced the provincial government to encourage farmers to practice water- 
harvesting and to store runoff water in caves and storage pits dug into the loess soil $[13,14]$.

\subsection{Changing wheat cultivation}

Spring wheat was a common crop of the SNHA for a long time. Scientists demonstrated the need to transform the production of winter wheat in the region, especially given the likelihood of climate warming that would potentially aggravate spring droughts $[15,16]$. Accordingly, they promoted a high yield winter wheat cultivation model that included the change from spring wheat to winter wheat cultivation. This important strategic measure greatly reduced food shortages, and increased the income of the local farmers and of the region as a whole [17]. New wheat cultivars with higher water us ability and anti-cold were also introduced [18].

\subsection{Establishing orchards}

One way to increase farm incomes was to establish orchards to produce fruits such as the Zaosu pear (a hybrid of Pyrus bretschneideri) that could be grown as a cash crop. Scientists developed techniques to establish efficient and profitable orchards in the SNHA utilizing microirrigation and intercropping systems with forage grasses or crops [19].

\subsection{Improving animal husbandry}

Providing families with a calf (for meat production) was found to significantly improve the economic status of the three families. For the first family with a calf when the calf has a baby, it could be sold for 3000 Yuan (RMB) to the second family. This will make the income for the first family. The second family carefully management of the baby cow for over six month and then sold it to third family for 6000 Yuan (RMB), and this will make the second family with the income of 3000 Yuan (RMB). The third family, who have good ability for fattening, with another few months management, this cow will become priority beeves and it could be sold for 10000 Yuan (RMB). It is saying that one cow could make three families to have income and make a profit. Scientists also promoted the strategic measure to develop improved grasslands alongside animal husbandry in SNHA [2]. This included alfalfa production but too much alfalfa in forage would lead to tympanites disease in cattle and sheep. It was necessary to also promote forage grass production such as corn, oat, sorghum or species mixtures (Fig. 1).

\subsection{Irrigation}

Some parts of the SNHA can access to irrigation water taken from the Yellow River. However, in general,
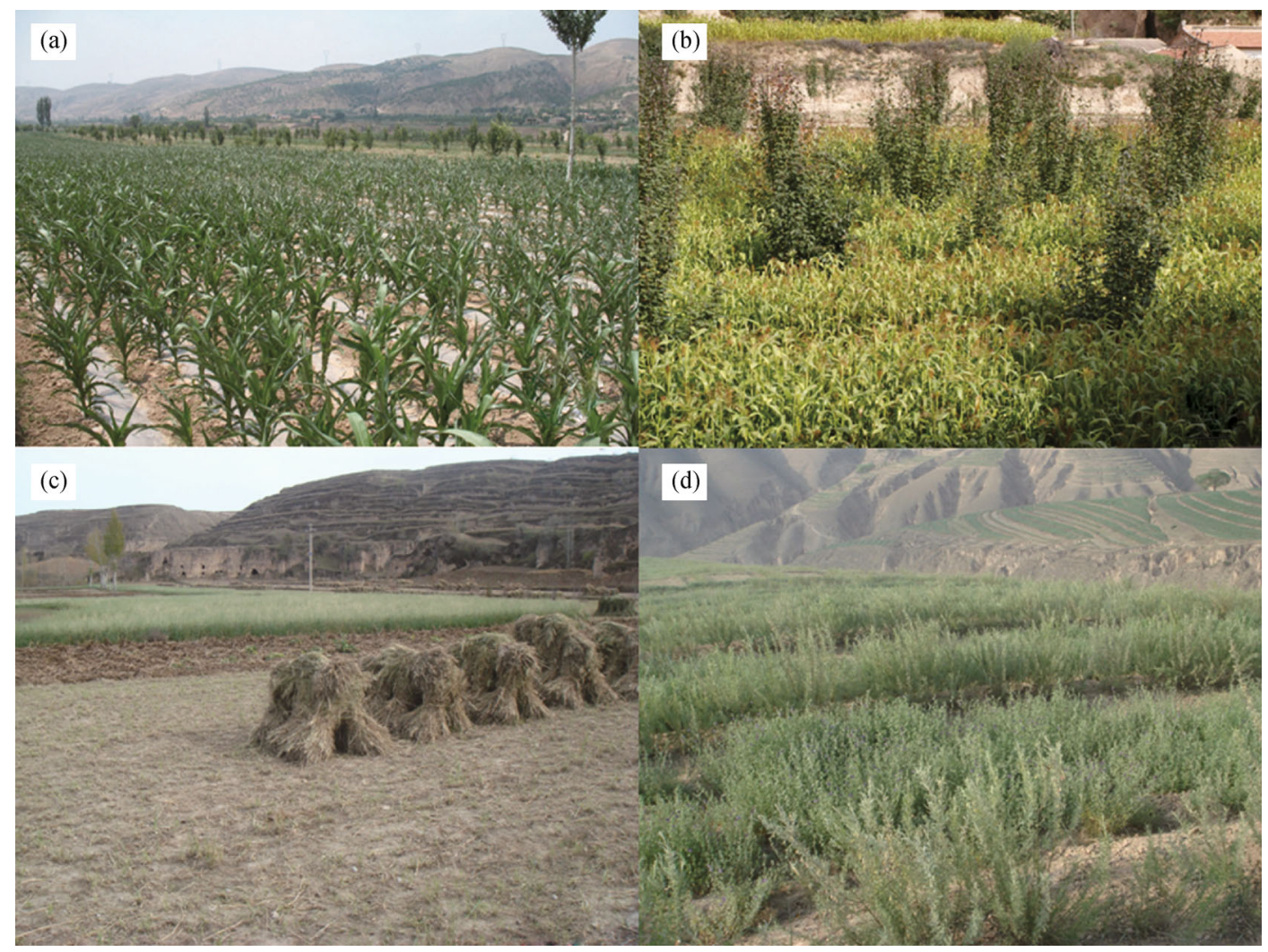

Fig. 1 The examples of forage grass plantings in Hechuan Country. (a) Maize with plastic film; (b) mixed grasses; (c) tetraploid oat (Avena magna); (d) alfalfa and Caragana korshinskii. 
irrigation was not a preferred strategy for developing the agriculture of the region. Instead, the focus was on dryland agricultural techniques that could rely on rainfall alone [20].

\subsection{Restoring the environment}

Restoring the environment involves assigning appropriate land use for specific locations and coordinating agriculture and animal husbandry with the restoration process. These concepts of environmental restoration were tested in certain areas, notably in Yuanzhou Distinct, Guyuan City.

\subsection{Revegetation}

The intent was to reverse the sequence of the ecological damage that had occurred (tree loss-shrub loss-grass losssoil erosion) with the plant succession following the sequence of grass-shrub-tree. Ecological restoration should follow natural processes otherwise the financial cost is excessive [21].

\subsection{Grassland}

Establishing grassland along with improved animal husbandry was a good strategy for a region in which the people had a long history of sheep and cattle husbandry. Later some scientists proposed to those villages be established to focus on the production of forage grasses [22]. The inclusion of leguminous forage crops such as alfalfa was also promoted. Panicum virgatum (switchgrass) was found to be able to survive the severest conditions, so ten cultivars were introduced from the United States [23,24]. Recent studies investigated their adaptation to the Loess Plateau and their influences on local forage grasses such as Achnatherum splendens [2527].

\subsection{Ecological migration}

The SNHA is typical in that the most impoverished population lives in areas where the potential for ecological restoration is the lowest and the damage to the environment is the most severe [3]. Even with the improvements in agriculture described above, parts of the area cannot sustainably support the human population and poverty remained a problem. The topography makes access to offfarm employment opportunities difficult. Therefore, the government of NHAR made the decision to move 350000 people from 1655 villages in SNHA to northern NHAR (Fig. 2). The aim was to reduce the population density, which averaged 80 per $\mathrm{km}^{2}$ reaching as much as 140 per $\mathrm{km}^{2}$, to levels that approach the UN recommended levels of 7-20 per $\mathrm{km}^{2}$ for such regions [8].

A well-ordered process of migration began in 2011 and should be completed by 2015 . People are being relocated

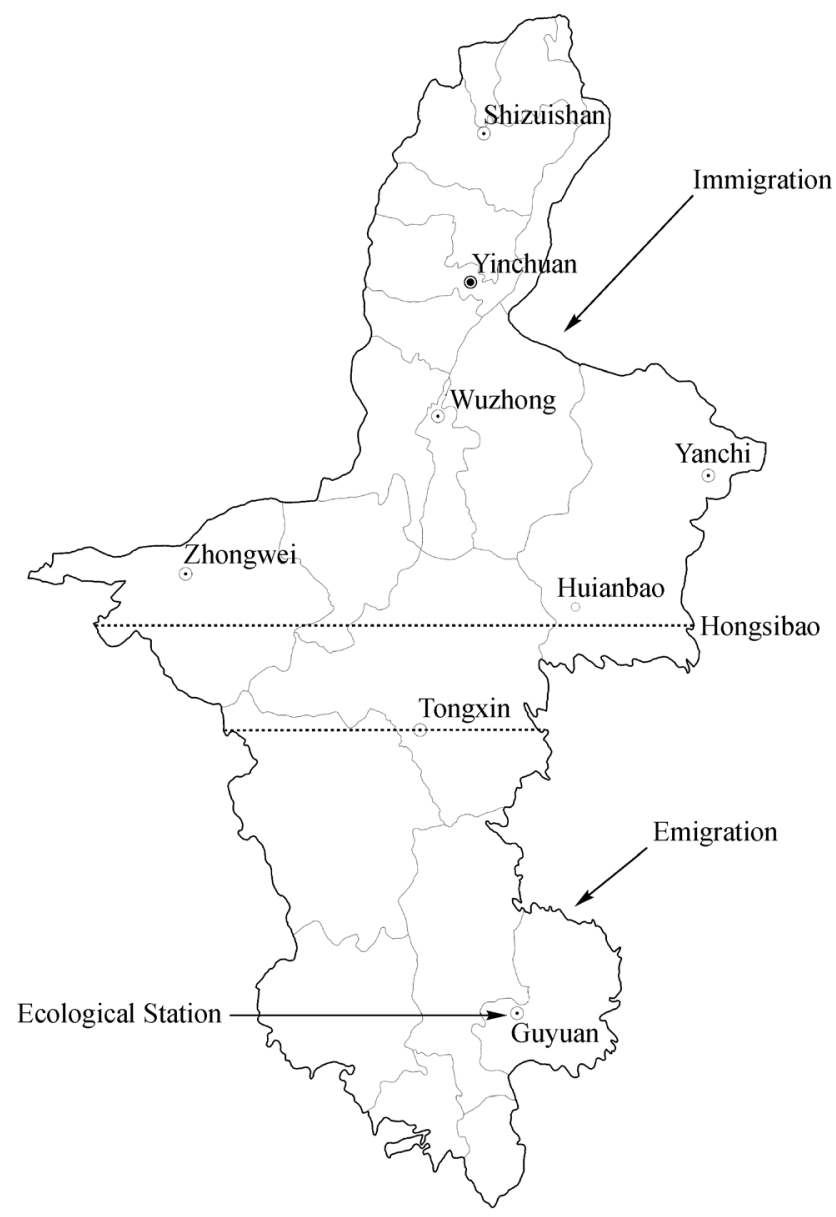

Fig. 2 Locations of Guyuan Ecological Station in NHAR and the place where the immigration and emigration taken place. South of Tongxin (the lower dash line) is the SNHA, where the emigration taken place. North of Hongsibao (the upper dash line) is the immigration taken place (picture made by Zhang Liang)

to 342 new settlements established near the main highway and the Yellow River. This will provide better access to employment opportunities as well as water and land resources. The settlement area will offer irrigated cropland, greenhouses, and facilities for animal husbandry. It should be noted that this program was not undertaken lightly. Although the idea is to improve their quality of life, removal of people from their historical homeland can still be traumatic.

Reducing the population in the SNHA should enable the agricultural areas to support the new population levels while lessening the impact of humans on the natural environment. However, it also reduces the labor force, so some adaptation of the existing agricultural systems will be needed.

\section{The achievements in experimental zone}

After 40 years of research, the Guyuan ecological experimental zone has provide a benchmark for compre- 
hensive experimental study at a high academic level and the demonstration of successful techniques that have helped develop sustainable practices. This research has greatly improved agronomic techniques increasing water use efficiency and has significantly developed dryland agriculture on the Loess Plateau [9]. At the same time, the theory of and techniques for vegetation restoration on the Loess Plateau have greatly improved.

The research taken in its entirety has permitted the development of an optimal structural model, and production technology for agriculture, forestry and animal husbandry [7]. Applied to environmental restoration in conjunction with agriculture, the research has facilitated the afforestation of suitable barren mountains, the establishment of grasslands, the terracing of slopes and the introduction of intensive agriculture to tablelands (Fig. 3). This has improved environmental health and has brought economic benefits to the farmers $[17,28]$. The integration of this technology into ecological agriculture management systems has been promoted by the NHAR government and the scientists from Institute of Soil \& Water Conservation, Chinese Academy of Sciences as the "Shanghuang Experience," which were defined as three "hua" and two "improvements." The first "hua" is saying that on the top of mountains is should be revegetation by shrub trees, in Chinese called "Lühua," the second "hua" is saying that on the slope which the angle is less that 15 degree should make terraced, in Chinese called "Ti Tian Hua" and the third "hua" is saying that in the valley with better soil water condition and plat farm field it should have preliminarily intensive agriculture by mixture cropping of fruit trees and vegetables and it was called "Gao Xiao Ji Yue Hua." The first "improvement" is to improve the scientific and cultural knowledge for local farmers and the second "improvement" is to improve the framers income and ecological benefit for the local environment. "Shanghuang" is the village name, where the scientists worked and summarized the above experiences, is located in Hechuan Town, Guyuan City, Ningxia Hui Autonomous Region. In 2001, the Ningxia Development and Reform Commission allocated 30 million RMB to promote the achievements in Yuanzhou Distinct, Guyuan City $[17,28]$.

\section{Conclusions}

With the continued ecological migration, the pressure of the human population on the ecology of the SNHA will ease to a certain extent. However, it has also brought new social problems. It is difficult to realize the aim of efficient intensive production of farmland. To make more effective use of the local land resource, rural areas development in the depopulated areas should give preference to agriculture. The basis of semi-arid agricultural systems should be

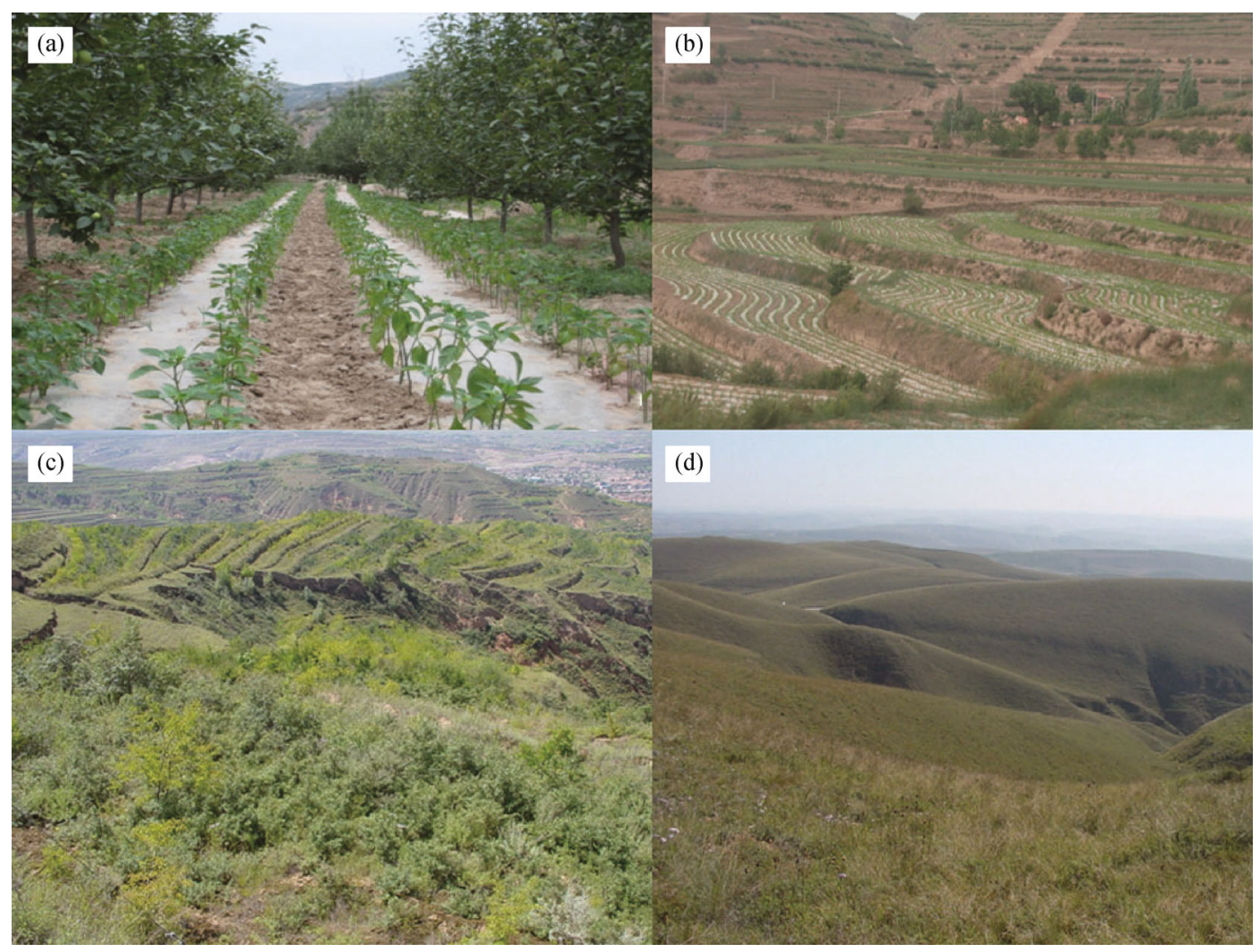

Fig. 3 Photographs showing the "Shanghuang Experience". (a) Preliminarily intensive agriculture; (b) terraced slopes; (c) revegetation of barren mountains (shrub and herbaceous plants); (d) revegetation of barren mountains (natural grassland species). 


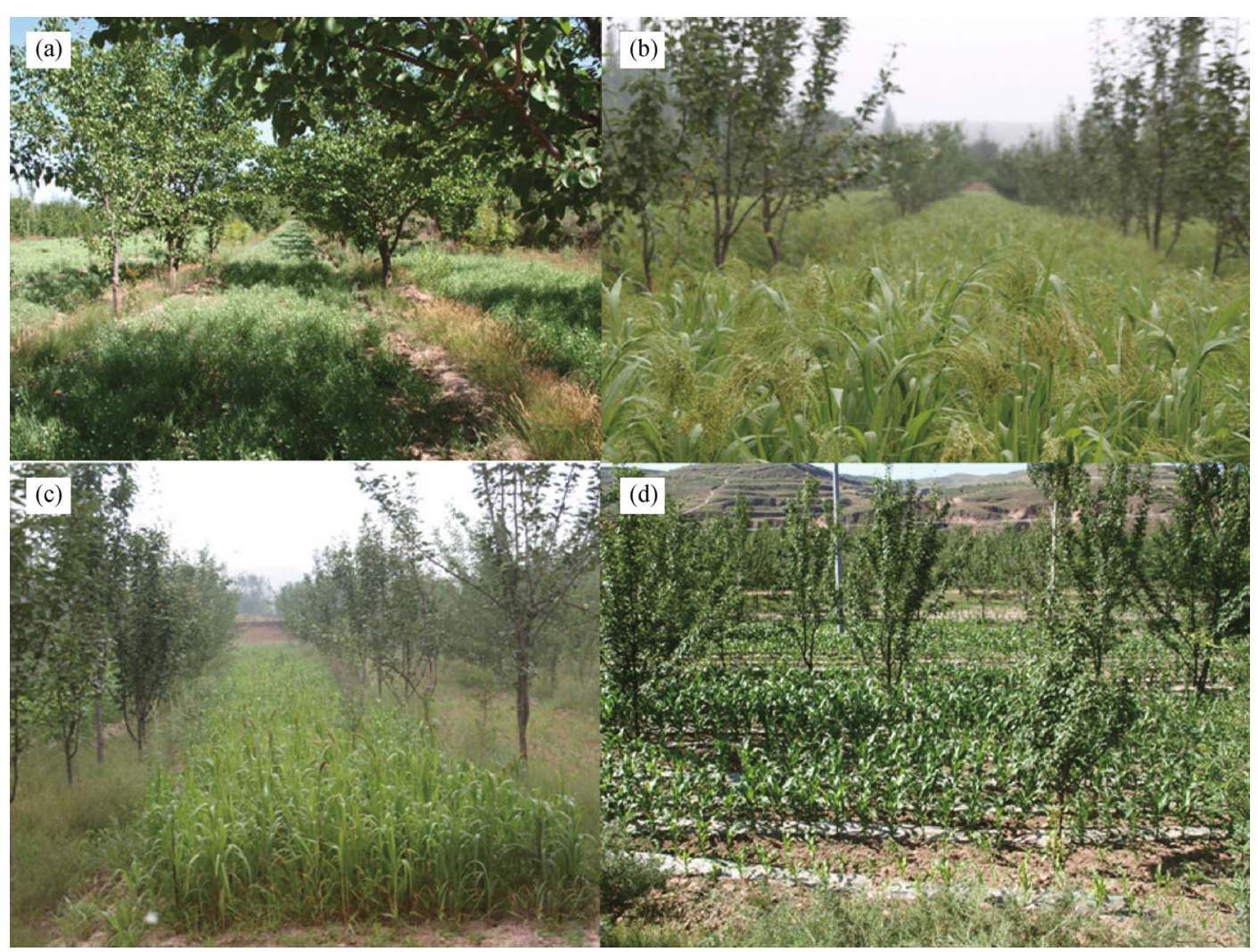

Fig. 4 Intercropping in Zaosu pear orchards in Hechuan County, Yuanzhou Distinct, Guyuan City. (a) grasses (mixture of sorghum and millet); (b) glutinous millet; (c) millet; (d) corn.

to plant grasses with breeding stocks. Farmland should produce forage crops including both legumes and grasses. More economical methods will encourage the planting of perennial forage grasses (e.g., A. splendens and $P$. virgatum) as well as annual forage grasses (Fig. 4). Such systems require less labor, and therefore solve the problem of the labor shortage induced by migration. Furthermore, they ensure a stable income for the farmers and stockowners that practice semi-arid agriculture. The farmers and herdsmen remaining in the SNHA should be encouraged to supplement irrigation water supplies by adopting the rainwater catchment method in parts of their land, so that they can increase the yield of perennial forage and thus reduce the need to purchase forage in winter and spring. This will permit them to sustain the present numbers of their cattle and sheep. In this way, farmers and herdsmen can achieve a stable income that will alleviate poverty and improve their lives.

Acknowledgements The authors thank Dr. Robert P. Marzec, Department of English, Purdue University, USA for language editing and thanks also giving to Dr. David Warrington who worked at the State Key Laboratory of Soil Erosion and Dryland Farming in the Loess Plateau, Institute of Soil and Water Conservation, Northwest A\&F University for the critical reading and language editing of this manuscript. It is greatly appreciated that this journal also invited patience and conscientious reviewers for the improvement of the manuscript. The authors also thank the Twelve Five National Science and Technology program (2011BAD31B05) for financial support.

Compliance with ethics guidelines Yongqing Ma, Jie Chen, Shuqi Dong and Lun Shan declare that they have no conflict of interest or financial conflicts to disclose.

This article does not contain any studies with human or animal subjects performed by any of the authors.

\section{References}

1. Guo G W, Chen X J, Zhu G Y. The selection of ecological rehabilitation model for south Ningxia hilly area. Journal of Ningxia Communist Party Institute, 2000, (2): 28-32 (in Chinese)

2. Jia Z K, Wang L X, Han Q F, Miao X W. Difficult conditions and way out for agricultural development in the mountain area in the south part of Ningxia. Ganhan Diqu Nongye Yanjiu, 1994, (12): 2633 (in Chinese)

3. Li W T, Han Q L, Dong P Z. Water-saving - The water using technique in the Mountain area of south Ningxia. Journal of Ningxia Agricultural College, 2000, (21): 66-69 (in Chinese)

4. Han Y W. The strategy of sustainable development in mountainous area of southern Ningxia. Research on Soil Water Conservation, 2005, (12): 5-7 (in Chinese)

5. Ma W L, Cui W H, Li Y J, Fang L. The practice of the 
comprehensive measure for soil and water loss in South Ningxia hilly area. Yellow River, 2000, (22): 30-31 (in Chinese)

6. Yang M L, Mi W B, Fan X G. Research on ecological agriculture under ecological reconstruction of south Ningxia hilly area. Research on Soil Water Conservation, 2005, (12): 180-183 (in Chinese)

7. Cheng J M, Chen G L. Study on comprehensive harnessing of small watershed in loess hilly area-Taking Shanghuang experimental area of Guyuan county as all example. Journal of Soil Erosion Soil Water Conservation, 1996, (2): 42-47 (in Chinese)

8. Li B C, An S S, Huang Z B, Chen L P. Study on strategy of ecology and environment construction and removing popularization with science and technology in dryland of Southern Ningxia. Ganhan Diqu Nongye Yanjiu, 2002, (20): 107-110, 115 (in Chinese)

9. Xin Y Q, Shan L, Sun J B, Liu Z M. Study on the technical system for raising the production of dryland farming in the southern Ningxia hilly area. Acta Conservation Soli ET Aquae Sinica, 1990, (4): 33-39 (in Chinese)

10. Xu M, Shan L, Guo L K. Study on the effects of gibberellin and calcium ions treatment on the seeds of spring wheat. Seeds, 1990, (48): 25-28 (in Chinese)

11. Shan L, Guo L K, Xu M, Sun J B. Effects of seed treatment with calcium and gibberellin mixture on physiological activities and yield increase under drought conditions. Ganhan Diqu Nongye Yanjiu, 1994, (12): 85-91 (in Chinese)

12. Lou C J, Shan L, Su P. Effects of $\mathrm{Ca}^{2+}$ and GA on spring wheat seedling formation. Tianjin Agricultural Science, 1997, (3): 25-27 (in Chinese)

13. Chen G L, Xu X X, Cheng J M, Guo Y X, Zhao S W. The Bases and potentialities of developing cellor water harvest and water saving agriculture in southern Ningxia hilly area. Research on Soil Water Conservation, 1996, (3): 2-7 (in Chinese)

14. Ma W L, Cui W H. The practice of rain water harvest and water saving irrigation in southern Ningxia mountainous area. Chinese Rural Water Recourses Water Power Electricity, 2000, (9): 11-12 (in Chinese)

15. Liu Y H, Dang Z C, Li D X. Study on seeds selection of winter wheat in Shanghuang experimental field. Research on Soil Water Conservation, 1996, (3): 81-85 (in Chinese)

16. Zhao S W, Chen G L. The effects of fertilizer apply methods on improving nitrogen transport and increasing crop yield. Research on Soil Water Conservation, 1996, (3): 179-184 (in Chinese)
17. Jin $Z$ P, Yan Q. The effective connection between science and technology with agricultural production-The hint and investigation of populization of Shanghuang experience in Hechuan town, Yuanzhou district of Guyuan city. Communist Party Members, 2004, (3): 30-31 (in Chinese)

18. Deng X P. New winter wheat variety of Ningdong No. 1. Crop Variety Resources, 1999, (3): 3 (in Chinese)

19. Shi L M. Development prospect and technological approaches of orchard construction in Southern Ningxia mountainous region. Bulletin of Soil Water Conservation, 1997, (17): 37-42 (in Chinese)

20. Shan L. Development of semi-dryland farming and sufficiently alleviation of water resources shortage of North China. Disaster Reduction of China, 2006, (11): 42 (in Chinese)

21. Xin W J, Ren X S. Given priority to the grass planting and development of the advantages of the regional economy in the southern mountainous area of Ningxia. Journal of Ningxia Agricultural College, 2003, (24): 56-58, 80 (in Chinese)

22. Ma H B, Chen Y L, Shen Y L. Discussion of the construction of practaculture village in the south Ningxia. Journal of Ningxia Agricultural College, 2003, (24): 17-30 (in Chinese)

23. Ichizen N, Ogasawara M, Kuramochi H, Konnai M, Sunohara W, Takematsu T. Screening of weeds for vegetation recovery in a pasture in the semi-arid region of the Loess Plateau in China. Weed Research of Japan, 1993, 38(3): 182-189 (in Japanese)

24. Ichizen N, Takahashi H, Nishio T, Liu G B, Li D Q, Huang J. Impacts of switchgrass (Panicum virgatum L.) planting on soil erosion in the hills of the Loess Plateau in China. Weed Biology and Management, 2005, 5(1): 31-34

25. Cheng J M. Fine soil and water conservation plant-Achnatherum splenden. Journal of Soil and Water Conservation, 2000, 14(4): 27 (in Chinese)

26. Shui J F, An Y, Ma Y Q, Ichizen N. Allelopathic potential of switchgrass (Panicum virgatum L.) on perennial ryegrass (Lolium perenne L.) and alfalfa (Medicago sativa L.). Environmental Management, 2010, 46(4): 590-598

27. Ma Y Q, An Y, Shui J F, Sun Z J. Adaptability evaluation of switchgrass (Panicum virgatum $\mathrm{L}$.) cultivars on the Loess Plateau of China. Plant Science, 2011, 181(6): 638-643

28. Ren A Q. The hint from Guyuan, Ningxia "Shanghuang Experience"-Strength of County scale economy. Research on Market Economy, 2004, 93(1): 84-85 (in Chinese) 